\title{
EL IMPACTO DE LA COOPERACION ESTRUCTURADA PERMANENTE (CEP) SOBRE LA COMUNIDAD DE SEGURIDAD EUROPEA
}

\author{
Francisco Salvador Barroso ${ }^{1}$ \\ Holy Spirit University of Kaslik (USEK)
}

\begin{abstract}
Resumen:
Según se desprende de las conclusiones del último Consejo Europeo celebrado durante los días 19 y 20 de diciembre de 2013, el tema de la defensa ha recobrado protagonismo en el seno del proceso de integración europea. La Unión Europea (UE) se encuentra ante un nuevo escenario estratégico donde la cooperación se presenta como la dinámica a seguir, y donde el mecanismo de la CEP tiene muchas cosas que decir. El objetivo de este artículo consiste por un lado, en analizar por qué y cómo la CEP se presenta como un elemento dinamizador de la propia Política Común de Seguridad y Defensa (PCSD), y por otro lado, en demostrar desde una visión constructivista como la CEP puede contribuir a crear una "comunidad de seguridad europea". Esto nos permitirá comprender como la PCSD más que un instrumento para mejorar las capacidades militares nacionales de los Estados miembros se presenta como un instrumento para mejorar el proceso de integración europea en materia de seguridad y defensa desde un punto de vista político.
\end{abstract}

Palabras clave: Unión Europea, integración europea, Política Común de Seguridad y Defensa, Cooperación Estructurada Permanente, comunidad de seguridad.

Title in English: "How Permanent Structured Cooperation Impacts on the European Defence Community"

\section{Abstract:}

It is clear from the conclusions of the European Council on 19 and 20 December 2013, that the issue of defense has regained prominence within the European integration process. The EU is facing a new strategic environment where cooperation is fundamental in this process and where the PEC mechanism has several important elements to provide. The objective of this article is on one hand, to analyze why and how the PEC is presented as a dynamic element for the CSDP itself, and on the other hand, to show from a constructivist point of view, how the PEC can help in the creation of a "European security community". All this will facilitate a better understanding on how the CSDP can be presented, from a political point of view, as a tool to improve the process of European integration, more than as an instrument to enhance national military capabilities of the EU Member States.

Keywords: European Union, European Integration, Common Security and Defense Policy, Permanent Structured Cooperation, Security Community.

Copyright () UNISCI, 2014.

Las opiniones expresadas en estos artículos son propias de sus autores, y no reflejan necesariamente la opinión de UNISCI. The views expressed in these articles are those of the authors, and do not necessarily reflect the views of UNISCI.

\footnotetext{
${ }^{1}$ Francisco Salvador Barroso Cortés es profesor auxiliar de Relaciones Internacionales y Geopolítica en el Instituto Superior de Ciencias Políticas y Administrativas de la Universidad Espíritu Santo de Kaslik (USEK)Líbano. Sus principales líneas de investigación se centran en el proceso de Europeización en materia de Seguridad y Defensa transformación de las Fuerzas Armadas, Geopolítica del Líbano y del Oriente Medio, movimientos insurgentes y otras formas de violencia política.

E-mail: franciscobarroso@usek.edu.lb.
} 


\section{Introducción}

Se han cumplido diez años desde la aparición de la Estrategia Europea de Seguridad (EES) y cinco años desde que apareció el informe sobre la aplicación de la EES (2008). Dicha aparición supuso un antes y un después en el proceso de integración europea en materia de seguridad y defensa. Lo curioso es que la puesta en común de retos y amenazas que hostigaban por aquel entonces a los europeos surgió como consecuencia de la falta de acuerdo existente en relación a la intervención de la Unión Europea (UE) en la guerra de Iraq. Ahora en su décimo aniversario contemplamos la necesidad de reconsiderar la validez, y efectividad de dicho marco estratégico comunitario como consecuencia de la falta de acuerdo en relación a la intervención o no de la UE en casos recientes como los de Libia, Mali y Siria. Sea como fuere, es la primera vez que el Consejo Europeo retoma con cierto ímpetu el tema de la defensa desde que lo hiciera en el 2008. Esta recuperación por el interés sobre la defensa podría hacernos pensar si es posible abrir de nuevo un proceso de evaluación y redefinición de la Política Común de Seguridad y Defensa (PCSD). Dicha dinámica de replanteamiento podría surgir como consecuencia del nuevo marco geoestratégico de la UE, así como del nuevo papel que podría jugar la UE en cuanto posible proveedor de seguridad en el escena internacional.

Según se desprende de las conclusiones del Consejo Europeo celebrado durante el 19 y 20 de diciembre de 2013, la cuestión de la defensa ha recuperado protagonismo al afirmar que la defensa es importante ${ }^{2}$. Dicho Consejo presentó como objetivos prioritarios, el aumento de la efectividad, la visibilidad y el impacto de la PCSD $^{3}$. Con estos tres objetivos generales parece que se ha abierto un nuevo proceso de reformulación de la propia PCSD, donde el factor de la cooperación se presenta como fundamental para la consecución de los mismos.

Para poder entender la importancia que ha recobrado la dinámica de la cooperación en el seno de la UE deberíamos de tener en cuenta el impacto de la crisis económica actual. De hecho, parece que estemos asistiendo a un aumento de lo que podríamos denominar como "economización de la seguridad"4. La búsqueda de la eficacia y eficiencia del gasto en defensa como consecuencia de la preocupación derivada de la austeridad ejemplificaría esta dinámica. Dicho proceso demandaría un replanteamiento tanto de la gestión económica como de las políticas que guarden relación con la seguridad y defensa. Lo lógico en este contexto sería apostar por economías de escala, y por racionalizar la defensa europea. De ahí, el interés que ha suscitado el mecanismo de defensa de la Cooperación Estructurada Permanente (CEP), así como el de la plataforma de cooperación que representa el Pooling \& Sharing (mancomunar y compartir). De hecho, esta plataforma permitiría garantizar a los Estados miembros de la UE y por ende, de la Organización del Tratado del Atlántico Norte (OTAN), parte de su cuota de soberanía en relación a dichos recursos materiales. Esto último se traduciría en una disminución de la dependencia de los Estados miembros en relación a la UE y la OTAN.

Además, dicha crisis está obligando en parte a reconsiderar el papel que la UE puede jugar en el contexto internacional. La falta de liderazgo, la vaguedad de su marco estratégico, así como la falta de cohesión política entre los 28 Estados miembros están implicando una

\footnotetext{
${ }^{2}$ Consejo Europeo de Bruselas, Conclusiones del Consejo Europeo, 19 y 20 de diciembre de 2013. Apartado 1.1, en http://www.consilium.europa.eu/uedocs/cms data/docs/pressdata/es/ec/140263.pdf.

${ }^{3}$ Ibid., p. 3.

${ }^{4}$ Coelmont, Jo: “A European Global Security Strategy: Offering Seven-League Boots to Become a Global Actor”, Egmont, Security Policy Brief, n45, Royal Institute for International Relations (marzo 2013), en http://www.egmontinstitute.be/papers/13/sec-gov/SPB45.pdf.
} 
pérdida de protagonismo de la UE en cuanto actor de la escena internacional. Cuatro think tanks europeos publicaron recientemente un informe centrado en la elaboración de una estrategia global europea ${ }^{5}$. Esta iniciativa lanzada por los ministros de asuntos exteriores de España, Italia, Polonia y Suecia plantea la necesidad de revisar la estrategia europea existente, así como el replanteamiento del rol que la UE debe y puede jugar en el escenario internacional. La UE necesita más que una nueva estrategia reactiva o defensiva, un nuevo mensaje que inspire su proyecto en la arena internacional ${ }^{6}$.

El objetivo de este artículo consiste por un lado, en analizar por qué y cómo la CEP se presenta como un elemento dinamizador de la propia PCSD, y por otro lado, en demostrar desde una visión constructivista como la CEP puede contribuir a crear una "comunidad de seguridad europea". Esto nos permitirá comprender como la PCSD más que un instrumento para mejorar las capacidades militares nacionales de los Estados miembros se presenta como un instrumento para mejorar el proceso de integración europea en materia de seguridad y defensa desde un punto de vista político.

Para ello, presentaremos los rasgos generales que presenta la cooperación en materia de seguridad y defensa. Explicaremos la naturaleza que presenta el mecanismo de defensa de la CEP, y abordaremos desde una perspectiva constructivista de qué manera la CEP y la plataforma de cooperación del Pooling \& Sharing pueden contribuir en la mejora del proceso de integración en materia de seguridad y defensa desde un punto de vista político. Además, explicaremos cómo dichos mecanismos pueden contribuir en relación al desarrollo de una identidad europea de defensa, que se presentaría a su vez como pilar de la comunidad de seguridad europea.

Para poder entender el impacto que las dinámicas de cooperación presentan en relación a los intereses, valores y principios de los diferentes Estados miembros de la UE en materia de seguridad y defensa, emplearemos el marco teórico que ofrece el constructivismo a través del análisis de las denominadas comunidades de seguridad.

Los constructivistas proponen que los factores sistémicos, así como la interdependencia y la convergencia trasnacional, derivan de los valores domésticos, y que se produce una manipulación de los símbolos en la estrategia de racionalización de los agentes. Todo ello, según los constructivistas, contribuiría a la formación de los intereses colectivos ${ }^{7}$. Sea como fuere, la relación entre los diferentes actores determina el comportamiento colectivo en esta materia de seguridad y defensa. Por lo tanto, el desarrollo de la PCSD representa esta evolución en cuanto a la conformación del interés colectivo que simboliza la UE como actor de la escena internacional. De hecho, explican la formación del interés nacional en función del comportamiento colectivo que se produce dentro de la estructura, y que determina los objetivos colectivos. Los Estados aprenderían a cooperar a través de un proceso de reconstrucción de sus intereses en términos de compromisos y normas sociales compartidas ${ }^{8}$.

\footnotetext{
5 "Towards a European Global Strategy. Securing European Influence in a Changing World”, IAI, Real Instituto Elcano, PISM, UI (28 May 2013), at http://www.iai.it/pdf/egs_report.pdf.

${ }^{6}$ Grevi, Giovanni: "A progressive European global strategy", FRIDE, Policy Brief, n40 (noviembre 2012), en http://www.fride.org/download/PB 140_A_progressive_European_global_strategy.pdf.

${ }^{7}$ Kubalkova, Vendeluka; Onuf, Nicholas y Kowert, Paul (1998): International Relations in a Constructed World, Nueva York, M.E. Sharpe, p.102.

${ }^{8}$ Wendt, Alexander: "Anarchy is what states make of it: the social construction of power politics", International Organization, vol. 46, n² (primavera 1992), p.417.
} 
Lo importante es tener en cuenta como sostienen los constructivistas, que la estructura por sí sola no explica la formación de la identidad, sino que tenemos que tener en cuenta tanto a los agentes como sus correspondientes comportamientos e interacciones en el seno de las instituciones que conforman. Todo ello, con vistas a poder comprender adecuadamente la formación de los procesos de creación de identidades. En este sentido y como presentaremos después, tanto la CEP como el Pooling \& Sharing se presentan con un potencial considerable para socializar y persuadir a los Estados participantes. Dichos procesos afectarían posteriormente sobre la identidad de dichos Estados, y sobre la manera en la que dichos actores interactúan habitualmente en las diferentes dinámicas de cooperación ofrecidas.

El artículo presenta la importancia que la cooperación presenta en relación al proceso de integración europea en materia de seguridad y defensa. Continúa analizando la importancia que presenta el Pooling \& Sharing en relación a las dinámicas de cooperación. En el siguiente apartado, abordamos el debate existente en relación al carácter inclusivo o exclusivo de la CEP. A continuación analizamos si el desarrollo registrado por la PCSD nos permite hablar de la existencia de una comunidad de seguridad europea acorde con el nivel de integración registrado hasta ahora. Finalmente, presentaremos los objetivos estratégicos de la CEP, así como su posible incidencia sobre la comunidad de seguridad europea.

\section{La importancia de la cooperación en el proceso de integración europea en materia de seguridad y defensa}

El tema de la cooperación entre Estados ha recobrado una importancia inusitada debido al contexto internacional actual. De hecho, son cada vez más los procesos de integración regional, así como la firma de acuerdos de colaboración bilateral, trilateral o multilateral que exponen la necesidad y la voluntad de los Estados de cooperar con otros actores del escenario internacional. Independientemente de esto último, tenemos que indicar que la cooperación y el conflicto en las relaciones internacionales dependen de la situación que estemos analizando. Por tanto, las dinámicas de cooperación y/o conflicto se encuentran siempre presentes en las dinámicas de interacción internacional.

Vivimos hoy día tiempos convulsos donde la aparición de amenazas de carácter transnacional ha desdibujado el papel central que jugaban otrora los Estados como entidades responsables de garantizar la seguridad y defensa de sus conciudadanos. Nos encontramos ante un contexto internacional globalizado, que no sólo ha creado nuevas oportunidades comerciales, sino que ha traído consigo nuevas amenazas y peligros. Este conjunto de amenazas transnacionales exigen a los Estados un replanteamiento de sus comportamientos habituales en relación a las cuestiones de seguridad y defensa. De hecho, ya no pueden hacer frente de manera unilateral a los nuevos riesgos y amenazas que hostigan la estabilidad y el orden internacional imperante. Como afirma Beck ${ }^{9}$, vivimos hoy en día en una sociedad del riesgo mundial donde los atentados terroristas protagonizados por Al Qaeda y sus acólitos, han acercado a los Estados, y han hecho que comprendamos mejor lo que significa la globalización como comunidad de destino a escala mundial frente a las tendencias de violencia y de destrucción.

Además, el contexto internacional actual se presenta cargado de conflictos, y crisis de diferente índole que comportan un aumento de la inseguridad e inestabilidad internacionales.

\footnotetext{
${ }^{9}$ Beck, Ulrich (2003): Sobre el terrorismo y la guerra, Barcelona, Paidós, p.19.
} 
El final de la Guerra Fría trajo consigo el comienzo del final del orden internacional basado en los Estados nacionales ${ }^{10}$. Se empezaba a percibir una tendencia a la tras-nacionalización derivada del aumento de la interdependencia estatal. Un dato que refleja con claridad esta sensación de desorden o inseguridad global lo muestra el hecho de que dieciséis años después de la finalización de la Guerra Fría, se registraron 118 conflictos localizados en 80 lugares diferentes ${ }^{11}$.

El aumento de la interdependencia como consecuencia de la crisis económica que azota a los países miembros de la UE, junto a la aparición de estas amenazas transnacionales, nos hace pensar que la dinámica que debe primar de cara a garantizar la seguridad y defensa de cada país es la de la cooperación a través de la coordinación de políticas que persigan los mismos objetivos. Y es aquí donde se plantea el cómo hacer compatible el aumento de la cooperación con el desarrollo del proceso de integración regional que implica una cesión cada vez mayor de cuotas de soberanía por parte de los Estados miembros.

Las dinámicas de cooperación interestatal en las relaciones internaciones se han visto potenciadas gracias a los procesos de integración regional. A esto, hay que añadirle el hecho de que el nivel regional ha recobrado de nuevo cierto protagonismo en cuanto a nivel de análisis se refiere. De hecho, hay autores que apuestan por la posibilidad de explicar el orden del mundo global a través de la existencia de potencias regionales ${ }^{12}$.

La importancia del regionalismo conectaría bastante bien con la importancia de la cooperación, así como con los desarrollos que han registrado los diferentes procesos de integración regional existentes. De hecho, las regiones se han hecho más porosas como consecuencia de la globalización ${ }^{13}$. Esto ha provocado que la cooperación a nivel intrarregional e interregional se hayan visto potenciadas.

En este sentido, tanto el proyecto de integración europea como la creación de la comunidad de seguridad europea ${ }^{14}$ tendrían que ser contextualizados dentro del proceso de regionalización. De hecho, tendríamos que hacer referencia al complejo de seguridad regional presentado por los profesores Barry Buzan, y Ole Waever. Dicho complejo de seguridad sería conformado por un grupo de Estados cuya preocupación en relación a su seguridad más elemental, se encontraría lo suficientemente próxima la una de las otras. Como consecuencia de esta proximidad, sus correspondientes estrategias, y políticas de seguridad nacionales no se podrían concebir de manera independiente. De hecho, tendrían que ser analizadas teniendo en cuenta, que se encontrarían influenciadas y condicionadas por las estrategias de seguridad

\footnotetext{
${ }^{10}$ Beck, Ulrich (2004): Poder y contra-Poder en la Era Global. La nueva economía política mundial, Barcelona, Paidós, p.18.

${ }^{11}$ Harbom, Lotta y Walensteen, Peter: “Armed Conflict and its International Dimensions, 1946-2004”, Journal of Peace Research, vol.42, n5 (2005), p.623.

${ }^{12}$ Buzan, Barry y Waever, Ole (2003): Regions and Powers. The Structure of International Security, Cambridge, Cambridge University Press, p.20.

${ }^{13}$ Acharcha, Amitav:'The emerging regional architecture of World Politics", World Politics, vol. 4 (julio 2007), p.632.

${ }^{14}$ Según Adler y Barnett (Adler, Emanuel and Barnett, Michael N. (1998): Security communities, Cambridge, UK; New York, Cambridge University Press): para poder comprender adecuadamente el proceso de evolución que se registra en todo el proceso de integración presentaron un modelo para explicar el proceso de integración a través de la distinción de tres fases claramente diferenciadas como son la "ascendant", "nascent" y "mature". Nosotros nos centraríamos para el caso de la CEP en esta última fase, puesto que presentaría la consolidación de los cambios registrados en la fase anterior, y se empezaría a ver la posibilidad de establecer un sistema de gobernanza institucional común entre los diferentes actores que operan en la misma estructura. Se consolidaría lo que se ha venido en denominando como "región cognitiva", que aparecería como la base sobre la que descansa el sistema institucional de cooperación interestatal.
} 
nacionales del resto de Estados participantes en dicho complejo de seguridad regional ${ }^{15}$. Dichos autores justificarían cualquier desarrollo en relación a la seguridad regional teniendo en cuenta patrones de amistad y enemistad ${ }^{16}$.

Además, tendríamos que tener en cuenta el concepto de "gobernanza de seguridad". Emanuel Adler y Patricia Greve, la concebirían como “... un sistema de reglas concebidas por individuos y actores corporativos con el objetivo de coordinar, administrar y regular su existencia colectiva en respuesta a las amenazas a su seguridad física..."17. Este sistema de gobernanza de seguridad descansaría principalmente sobre un sistema de normas fundamentadas en una autoridad política, y un acuerdo en relación a unas normas, prácticas, $e$ instituciones consensuadas. Además, dicha gobernanza tendría en consideración el conjunto de identidades, racionalidades, tecnologías, y formas espaciales ${ }^{18}$, sobre y a través de las cuales se celebrarían las actividades relacionadas con la seguridad transnacional.

En relación a la dinámica de cooperación registrada en el seno de la UE en materia de seguridad y defensa, debemos indicar que normalmente se ve fomentada en función de los cambios estructurales que se registren en el sistema internacional ${ }^{19}$. De hecho, el aumento de la interdependencia a nivel global, el impacto de las amenazas transnacionales, el nuevo rol estratégico que juegan los Estados Unidos (EEUU) en relación a la seguridad de los europeos y que afecta al vínculo transatlántico, la reducción de los presupuestos nacionales dedicados a la defensa como consecuencia de la crisis económica, etc..., hacen que los Estados perciban la cooperación como la mejor de las maneras para garantizar su propia seguridad.

Para el caso que nos ocupa, parece que cuando estamos hablando de la UE estamos hablando de un proyecto inacabado ${ }^{20}$. Es cierto que se encuentra expuesta a una serie de factores de carácter endógeno (procesos de ampliación, por ejemplo), y exógeno (guerras, crisis internacionales, etc...), que obligan a este sujeto tan sui generis del panorama internacional a tener que adaptarse continuamente. Sea como fuere, el proceso de integración regional se ha ido consolidando poco a poco, incluyendo al ámbito de la seguridad y defensa. El objetivo que persigue dicho proceso de integración no es otro que el de conseguir materializar una defensa común europea. En este sentido, la cooperación entre los Estados se presenta a priori como el elemento fundamental para que dicha dinámica de integración logre finalmente tal objetivo.

En este sentido tendríamos que destacar como iniciativas más relevantes de cooperación en materia de defensa en el seno de la UE, el Tratado de Defensa Franco-Británico, la cooperación entre los Estados Visegrad (República Checa, Hungría, Polonia y Eslovaquia), el Triángulo de Weimar (Alemania, Francia y Polonia), y la iniciativa Ghent. En general,

\footnotetext{
${ }^{15}$ Buzan, Barry (1981): People, States and Fear: An Agenda for International Security Studies in the Post-Cold War Era, 2nd Edition, Hertfordshire, Harvester Wheatshea (1991 and 2008 with a new preface from the author), p. 190.

${ }_{16}$ Buzan, Barry y Waever, Ole (2003): Regions and Powers. The Structure of International Security, Cambridge, Cambridge University Press, p.53.

${ }^{17}$ Adler, Emanuel y Greve, Patricia: "When security community meets balance of power: overlapping regional mechanisms of security governance", Review of International Studies, n³5 (2009), p.64.

${ }^{18}$ Ibid., p.64.

19 Jones, Seth G. (2007): The rise of European Security Cooperation, Cambridge, Cambridge University Press,

p.31.
${ }^{20}$ Bauman, Zygmung (2006): Europa, una aventura inacabada, Madrid, Ediciones Losada, p.13.
} 
podríamos decir que a pesar de que hasta la fecha, se han alcanzado algunos desarrollos ${ }^{21}$, no podemos decir que hayan estado al nivel de lo esperado. Además, en algunos casos se han registrado iniciativas repetidas o que se bloqueaban entre ellas. Sirva de ejemplo, el hecho de que el Tratado de Defensa Franco-Británico repetía más o menos el proyecto que la Agencia Europea de Defensa (EDA) estaba llevando a cabo en relación a la limpieza de minas. A esto último habría que añadir el hecho de que en muchas ocasiones dichas propuestas de cooperación, en vez de pretender conseguir una mejora de la capacidad militar europea, lo que han pretendido es satisfacer determinados objetivos nacionales.

Antes de continuar nuestro análisis deberíamos preguntarnos, qué es lo que entendemos por cooperación. En este sentido, entenderemos por cooperación, aquella situación que se produce cuando los actores ajustan sus comportamientos a las preferencias reales o previstas de otros a través de los procesos de coordinación de políticas. Es en este ámbito donde tendríamos que tener en cuenta el papel coordinador que podría ejercer la EDA en relación al mecanismo de la CEP. De hecho, dicha agencia se presenta como la plataforma ideal para llevar a cabo la CEP, ya que la EDA intentaría coordinar las políticas de adquisición y determinaría las deficiencias que la UE tenga en el ámbito de la capacitación militar ${ }^{22}$.

En este contexto la EDA ejercería el papel de mediador y coordinador, de modo que todos los Estados miembros de la UE tendrían que ajustarse a los estándares fijados por el mecanismo de la CEP. Además y desde un punto de vista psicológico, la EDA también haría participe de alguna manera a todos los socios implicados en las reparticiones de los incentivos que ofrece el mecanismo, y podría animar a los que todavía no participan para que lleven a cabo el esfuerzo necesario para garantizar su inclusión y participación en el seno del mismo. Por tanto, la Agencia se presentaría como un instrumento esencial para la consecución de la interoperabilidad militar entre los distintos miembros de la UE.

Teniendo en cuenta dicha definición, tendríamos que analizar la dinámica de desarrollo que el proceso de integración europea registre en cada momento. En este sentido, y para el caso que nos ocupa, intentar conseguir el objetivo de la defensa común europea, además de presentarse como algo bastante ambicioso, ha despertado muchos recelos, y bastante desconfianza. Todo ello, debido a la concepción tradicional que existe en relación a la seguridad y defensa nacional, que se siguen presentando como elementos clave de la soberanía estatal. Sea como fuere, este recelo inicial se ha ido moderando gracias al contexto internacional que nos ha tocado vivir.

El contexto de seguridad y defensa ha registrado una serie de transformaciones que han demandado una nueva estrategia para poder hacer frente a los nuevos retos y amenazas que presenta. En este sentido, lo que no está claro es si la estrategia empleada para hacer frente a estas nuevas amenazas es la más idónea o no. Cuestión esta que se enlaza con la puesta en entredicho de la propia viabilidad de algunos de los procesos de integración regional. Sirva de ejemplo, la actual situación por la que está atravesando la UE. De hecho, se encuentra sometida al azote de una fuerte crisis económica que pone en entredicho no sólo el equilibrio entre los principios que inspiran su comportamiento como son los de la solidaridad y efectividad, sino también la propia viabilidad y supervivencia del proyecto comunitario. La

\footnotetext{
${ }^{21}$ Hasta ahora se han registrado algunos desarrollos en relación a los Poolings. Sirvan de ejemplo, el programa de entrenamiento de helicópteros militares, el satélite de comunicaciones europeo, y el programa sobre reabastecimiento en vuelo (air to air refuelling).

${ }^{22}$ El Consejo Europeo ha invitado a la EDA a examinar los pasos que deberían seguir los Estados miembros con vistas a cooperar más efectiva y eficientemente en proyectos de adquisición que se lleven a cabo a través de la plataforma de los Poolings.
} 
cuestión que se plantea ahora es analizar el impacto que la crisis está teniendo en relación al aumento de la lógica del riesgo, puesto que podría derivar en un aumento de la cooperación entre los Estados miembros de la UE, y por ende, en la superación del Estado nacional ${ }^{23}$.

En momentos de crisis económica las cuestiones relacionadas con la seguridad y defensa demandan una nueva perspectiva, que desde que se aprobó el Tratado de Lisboa pivota en torno al aumento de la cooperación entre todos sus Estados miembros. De hecho, el Tratado de Lisboa presentó varias propuestas como fueron la de la "Cooperación Estructurada Permanente" (CEP), y la "Cooperación Reforzada" $(\mathrm{CR})^{24}$. Esto nos indica que para avanzar en el ámbito de la seguridad y defensa europea, los decisores comunitarios apostaron por el término flexibilidad como la única vía para conseguir desarrollos en materia de PCSD.

Junto a esta situación coyuntural de crisis, tenemos que hacer referencia al problema que plantea el análisis de la UE en cuanto actor sui generis. De hecho, son varios los factores que convierten a la UE en un actor bastante especial. Se trata de un actor internacional que debe hacer frente a una serie de retos endémicos y exógenos bastante difíciles de gestionar. Las diferentes percepciones que existen sobre el propio proyecto comunitario, las diferentes percepciones que existen en relación a lo que es o debería de ser la PCSD, así como la existencia de una pluralidad de idiosincrasias, hacen que en esta materia, la UE tenga que superar más barreras y solventar más problemas. Además, la diferencia en cuanto a capacitación y recursos defensivos de los diferentes Estados miembros, hace que el esfuerzo en defensa no sea equitativo ${ }^{25}$, y esto a la postre, se traduce en un factor limitador ante cualquier posible iniciativa de desarrollo conjunto. A esto habría que añadir el hecho de que los Estados miembros de la UE buscan hacer más con menos ${ }^{26}$.

Asimismo tenemos que tener en cuenta la filosofía que inspire al proceso de integración en ese momento. Tenemos que ver que las diferentes áreas integración se inspiran de manera diferente. En el área de la integración en seguridad y defensa, la filosofía que predomina es la de la necesidad. Los Estados parecen que no cooperan por convicción sino, que apuestan por cooperar porque es la mejor de las maneras para disminuir sus correspondientes gastos en defensa. Sea como fuere, lo que hay que tener en cuenta es que, independientemente de la vocación que se tenga, se van registrando avances en el ámbito de la cooperación.

Esta cuestión del espíritu del proceso de integración nos permitirá comprender, como los Estados deciden apostar por la cooperación en plataformas como las que presenta la CEP. Además nos hará comprender como no hay que ver o concebir a la PCSD como un sistema en donde cada actor negocie sus intereses con el resto, sino más bien como un proceso donde los intereses, y las identidades de los diferentes sujetos se van ajustando y transformando ${ }^{27}$. De hecho, lo que pretendemos con este artículo es demostrar si la UE constituye o no una auténtica "comunidad de seguridad" desde un punto de vista constructivista. Esto nos permitirá calibrar el grado de integración europea en materia de seguridad y defensa que

\footnotetext{
${ }^{23}$ Beck, Ulrich (2012): Una Europa alemana, Barcelona, Paidós, p. 55.

${ }^{24}$ Ambas modalidades de cooperación han sido recogidas en el Tratado de Lisboa por los artículos n ${ }^{\circ} 42 \mathrm{y} \mathrm{n}^{\circ} 20$ respectivamente.

${ }^{25}$ Según datos ofrecidos por la Agencia Europea de Defensa (EDA) para el 2011, los diez países que más gastaban en defensa representaba el $90 \%$ del presupuesto total de la UE en materia de defensa. Por tanto, más de la mitad de los Estados miembros de la UE contribuían con menos de $1 \%$ del total. Ver: http://www.eda.europa.eu/docs/default-source/news/national-defence-data-2011---eda-pms.pdf.

${ }^{26}$ Biscop, Sven; Howorth Jolyon y Giegerich, Bastian: "Europe: a time for Strategy", EGMONT Paper $\mathrm{n}^{\circ} 27$, Royal Institute for International Relations (enero 2009), en http://www.egmontinstitute.be/paperegm/ep27.pdf.

${ }^{27}$ Tonra, Ben: "The European Union's Global Role", FORNET Working Group 1: Theories and Approaches to the CFSP, London School of Economics, n1 7/8 (noviembre 2003).
} 
existe a día de hoy, así como el potencial dinamizador que la CEP presenta en relación a la PCSD.

En este sentido, y para que el proceso de integración triunfe, parece imprescindible que tengamos que contar con la existencia tanto de un sentido de comunidad, como de una serie de instituciones y prácticas consolidadas. Sería en este punto, donde el desarrollo normativo e institucional gozaría de cierto protagonismo. Por lo que deberíamos preguntarnos hasta qué punto la CEP podría contribuir, a través de las dinámicas de cooperación que ofrece, a la creación de dicho sentimiento de pertenencia, y como dicho sentimiento de pertenencia podría consolidar una autentica comunidad de seguridad europea.

De hecho, dicho entramado podría recoger este sentimiento de pertenencia a un determinado colectivo. Dicho sentimiento de pertenencia generaría al mismo tiempo, una especie de compromiso en relación a dicha comunidad. Ambos sentimientos conformarían la base sobre la que descansa toda comunidad de seguridad. Por lo tanto, el mecanismo de la CEP, el papel de la EDA, y la plataforma de cooperación que ofrece el Pooling podrían contribuir al proceso de consolidación de una identidad común a través del proceso de socialización y persuasión que se registren en su interior.

El tema es comprobar cómo la CEP abarcaría aquella área de cooperación de la PCSD donde los Estados apuestan por la cooperación en vez de decantarse por la armonía o la discordia $^{28}$. De hecho, el mecanismo de defensa que representa la CEP, reflejaría una dinámica de cooperación que se mueve en torno a una serie de variables en las que los Estados pueden negociar su participación, sin ceder en este caso mucha cuota de soberanía.

En este ámbito y debido a las posibilidades que ofrece en relación a la cooperación interestatal, tendríamos que destacar el tema del Pooling \& Sharing. Para comprender dicha modalidad de cooperación deberíamos destacar la importancia que tuvo la denominada "iniciativa de Gante (Ghent Initiative)"29 que fue lanzada por Alemania y Suecia en noviembre de 2010, y aceptada por todos los miembros de la UE. De acuerdo con esta iniciativa todos los Estados miembros de la UE debían de evaluar y categorizar sus correspondientes capacidades militares teniendo en cuenta los criterios de eficacia operativa, eficiencia económica e implicaciones políticas. En relación a esto último tendríamos que destacar la labor de la EDA. Esta agencia podría seguir el trabajo de la iniciativa de Gante, ya que los Ministros de Defensa de los Estados participantes en la EDA han llegado a un acuerdo para elaborar un inventario de proyectos donde dichos Estados podrían cooperar con vistas a solventar las carencias operativas comunes a través de los Poolings.

El objetivo de dicha iniciativa consistía en preservar y desarrollar las capacidades nacionales a nivel operativo. Si bien estas capacidades específicas que se consideran esenciales permanecerán exclusivamente bajo responsabilidad nacional, otras capacidades sí que se podrían combinar o compartir entre algunos o todos los Estados miembros. De esta manera, las ineficiencias en el gasto de defensa serían superadas con este proceso de consolidación de capacidades.

\footnotetext{
${ }^{28}$ Keohane, Robert O. (ed. 2005): After Hegemony. Cooperation and Discord in the World Political Economy, Princeton, Princeton University Press, p.53.

29 "Pooling and sharing. German-Swedish iniciative. Food for thought", Ghent Ministerial

Meeting. Belgium presidency (noviembre de 2010), en

http://www.europarl.europa.eu/meetdocs/2009_2014/documents/sede/dv/sede260511deseinitiative /sede260511 deseinitiative en.pdf.
} 
En relación a esta modalidad de cooperación tendríamos que hacer referencia a la complementariedad que presenta dicha iniciativa con la "Smart Defence" de la OTAN. De hecho, se trataría de un intento por mejorar la integración militar de los países miembros. La idea es garantizar el establecimiento de una estrategia de adquisición donde se definan los programas comunes en base a necesidades detectadas de manera que se pongan en marcha especies de Poolings Lo interesante es que se presenta más o menos con los mismos objetivos que la iniciativa Gante. Con ello, la UE se podría ver beneficiada de los resultados que dicho programa presente en relación a los países de la UE que forman parte a su vez de la OTAN.

La modalidad de cooperación de los Poolings se materializaría cuando varios Estados miembros deciden organizar el uso de sus capacidades sobre bases colectivas. Esto involucra una estructura integrada para organizar el uso de las capacidades nacionales. En el seno del Pooling \& Sharing tenemos que dejar claro una cosa bastante importante, y es que la propiedad de los activos es todavía nacional, siendo los Estados miembros los que deciden si delegan o no el uso de sus activos en una organización integrada.

En cuanto a los objetivos que persigue el Pooling podríamos señalar los siguientes:

1. Mejorar la interoperabilidad y efectividad de las capacidades.

2. Fomentar los acuerdos multilaterales.

3. Alentar los proyectos de cooperación en relación al armamento y procedimientos comunes de adquisición para conseguir los resultados deseados.

Por tanto, los Poolings presentan una importancia bastante considerable, ya que se erigen en potenciales dinamizadores de la cooperación interestatal en materia de capacitación militar. En este sentido y de cara a comprender mejor esta plataforma de cooperación en materia de capacidades militares deberíamos especificar los factores que inciden y aconsejan el empleo de los mismos. Entre ellos podríamos destacar los siguientes:

1. Presión presupuestaria del gasto en defensa que los Estados de la UE pueden asumir. De hecho, la tendencia de los presupuestos destinados a las cuestiones de seguridad y defensa en vez de aumentar tiende a mantenerse en el mejor de los casos, o en su defecto tienden a decrecer. Por este motivo la aparición de este tipo de vías de cooperación y colaboración se reciben con los brazos abiertos porque implica un ahorro considerable en cuanto al gasto en defensa se refiere. Cada Estado puede colaborar de alguna manera con los recursos que tiene, sin ver incrementado su esfuerzo presupuestario en materia de capacitación militar.

2. Del mismo modo y en estrecha relación con el factor anterior deberíamos de destacar que el coste del mantenimiento de capacidades es menor con los Poolings que de manera independiente.

3. Los Poolings desde un punto de vista prospectivo beneficiarán la interoperabilidad sobre el terreno y por lo tanto, ayudarán en la armonización. Esto será una de las consecuencias que el fomento y empleo de los Poolings traerá consigo a medio y largo plazo. La apuesta en común de capacidades junto al aumento de operaciones conjuntas, ayudará a aumentar tanto la armonización como la mejora de la interoperabilidad entre las distintas FFAA. 
En cuanto a los posibles tipos de Poolings que podrían formarse podrían señalar los siguientes $^{30}$ :

1. Capacidades compartidas (Sharing Capabilities) donde los Estados miembros crean capacidades comunes a través de la provisión de capacidades nacionales. Se caracteriza además, porque no existe ninguna estructura que organice su uso.

2. Pooling de capacidades (Pooling Capabilities) que supone una estructura integrada para organizar el uso de las capacidades nacionales ${ }^{31}$.

3. Pooling a través de adquisición (Pooling though acquisition) donde las capacidades nacionales no existen, y son sustituidas en favor de capacidades multilaterales y organización multilateral propia. Un ejemplo práctico de este tipo de Pooling lo conformaría el proyecto que lleva a cabo la OTAN en relación a los aviones de alerta temprana NATO AWACS ${ }^{32}$.

4. Papel compartido (Role Sharing) a través de los cuales ciertas capacidades son rechazadas porque hay otro Estado que asume la responsabilidad de hacer lo que se tenga que hacer.

En este sentido y a efectos de ver la participación de los distintos Estados que conforman el proyecto comunitario en los Poolings, podríamos hacer referencia a lo que se ha venido llamando como la técnica de la "lista de bodas". Esto quiere decir, que con el fin de poder participar en la CEP, los Estados miembros deberían respetar los compromisos generales descritos en el Protocolo 10 anexo al TUE y llevar a cabo una cierta aportación militar a lo que podríamos llamar el bien común de la PCSD.

Esta modalidad de cooperación está siendo empleada por algunos de los países que conforman el proyecto comunitario. Así, y como ejemplos destacados de Poolings podríamos señalar uno donde sólo participan países miembros de la UE, y otros dos donde países de la UE participan en el seno de la OTAN. De esta forma tendríamos los siguientes ejemplos:

1. European Airlift Coordination Centre (EACC) en Eindhoven por parte de Francia, Alemania, Reino Unido, España, Bélgica, Holanda y Noruega.

2. NATO's AWACS- que se presenta como el mejor ejemplo de Pooling por adquisición.

3. La base aérea multinacional de Geilsenkirchen en Alemania, donde operan 17 Boeing NATO E-3A aircraft. Este Pooling se encuentra conformado por catorce países como Bélgica, Canadá, Dinamarca, Alemania, Grecia, Hungría, Italia, Holanda, Noruega, Polonia, Portugal, España, Turquía y EEUU

\footnotetext{
${ }^{30}$ Maulny, Jean Pierre y Liberti, Favio: "Pooling of EU Member States Assets in the Implementation of ESDP", Dirección General de Política Exterior de la Unión Europea, Parlamento Europeo (febrero 2008), en http://isiseurope.eu/sites/default/files/publications-downloads/2008_artrel_142_08-02epstudy-pooling.pdfl.

${ }^{31}$ Un ejemplo de este tipo de Pooling lo representa el European Airlift Coordination Centre (EACC) en Eindhoven por parte de Francia, Alemania, Reino Unido, España, Bélgica, Holanda y Noruega.

${ }^{32}$ Este proyecto se presenta como el mejor ejemplo de Pooling por adquisición. Se lleva a cabo en la base aérea multinacional de Geilsenkirchen en Alemania, donde operan 17 Boeing NATO E-3A aircraft. Se encuentra conformado por catorce países: Bélgica, Canadá, Dinamarca, Alemania, Grecia, Hungría, Italia, Holanda, Noruega, Polonia, Portugal, España, Turquía y EEUU.
} 
En toda esta dinámica de cooperación habría que destacar la labor de la EDA. Esta agencia es responsable de la determinación de las contribuciones, la supervisión del progreso en relación a los criterios establecidos con anterioridad y el desarrollo que necesita, así como su actualización continua. Además, la Agencia se encarga de ofrecer las oportunidades necesarias para garantizar la cooperación entre los diferentes Estados.

El papel de la Agencia debe seguir siendo central en la coordinación con el resto de instituciones y organismos de la UE, como pudieran ser los casos del Consejo y de la Comisión. No debemos excluir ninguna forma de representación del mecanismo de cara a poder reflejar mejor las complementariedades y concordancias en cuanto a intereses se refiere, teniendo en cuenta los requisitos comunes y/o en base a la cooperación reforzada "regional".

Todo ello, hace que la EDA se convierta en el centro de gravedad institucional para la puesta en práctica del mecanismo de la CEP. Por tanto, no hay que ver a este mecanismo como un instrumento que intente competir con la EDA, sino más bien como todo lo contrario, puesto que debe reforzar la eficacia de las actividades que implemente la Agencia.

Si la UE necesita generar sinergias de colaboración y cooperación entre sus diferentes miembros, la generación de Poolings ad hoc se presenta como la plataforma ideal para garantizar que cada Estado independientemente del peso que tenga en el proyecto comunitario contribuya de alguna u otra forma a la formación de unidades multinacionales De hecho, los Poolings se presentan como la mejor de las maneras posibles para garantizar tanto el incremento de la soberanía de los Estados miembros en materia de integración defensiva, como para permitir la participación de los Estados con menos peso en las operaciones de gran escala que la UE decida llevar a cabo.

\section{La Cooperación Estructurada Permanente (CEP) ante el debate entre la inclusión y la exclusión}

En este contexto de cooperación interestatal hay que señalar la importancia que presenta el mecanismo de la CEP. Dicho mecanismo surge en un contexto donde el proceso de integración regional demanda un mayor compromiso en materia de seguridad y defensa, pero en el que al mismo tiempo, debe ajustarse a las limitaciones que presenta la crisis económica actual. Crisis que se traduce en una serie de recortes de los presupuestos destinados a la seguridad y defensa. Sea como fuere, la CEP presenta una plataforma de cooperación ${ }^{33}$ que puede venir motivada por diferentes razones, y en donde la flexibilización se presenta $a$ otrora como la fórmula ideal para favorecer todo tipo de procesos de colaboración y cooperación entre Estados en materia de seguridad y defensa.

Por tanto, el reto que se le presenta a la UE consiste en cómo hacer más fuerte y efectiva su PCSD sin provocar divisiones. La clave de esta cuestión podría descansar sobre el mecanismo de la CEP. Dicha modalidad de cooperación nos presenta la línea a seguir, ya que

\footnotetext{
${ }^{33}$ Entre las modalidades de cooperación podríamos destacar las siguientes: Cooperación tácita, Cooperación negociada, o Cooperación impuesta. Véase: Milner, Helen: "International Theories of Cooperation among Nations. Strenghts and Weaknesses”, World Politics, n44 (abril 1992), pp.468-469.
} 
apostaría por hacer compatible un aumento de la solidaridad con un aumento de la convergencia en materia de seguridad y defensa ${ }^{34}$.

En este sentido, tendríamos que indicar que la voluntad de cooperar se vería fomentada por la necesidad en la consecución de intereses comunes. De este modo, la cooperación intergubernamental que a la postre es la que marca la naturaleza de la política objeto de nuestro análisis, como es la PCSD, tendría lugar cuando las políticas son realmente seguidas por unos gobiernos en pos de la consecución de intereses que se presentan como comunes ${ }^{35}$. No debemos olvidar el hecho de que los actores son percibidos como racionalmente egoístas. Por tanto, para poder entender el acto propio de cooperar, debemos entender previamente cuáles son las expectativas y creencias compartidas que se registran en el seno de la institución.

Para comprender las diferentes sensibilidades que presentan los Estados de cara a cooperar podríamos hacer referencia a los siguientes indicadores ${ }^{36}$ :

1. La estimación de la ganancia en función de las obligaciones y limitaciones que la cooperación va a comportar.

2. Concebir o no que se parte con ventaja al comienzo de las negociaciones y viceversa.

3. El tiempo de inversión en la cooperación de manera que el Estado pueda transformar sus déficits a través de los sucesivos acuerdos que implique la cooperación.

4. La previa experiencia del Estado en relación a determinados asuntos.

5. El tipo de relación existente entre ese Estado y el resto de actores que conforman el sistema.

Dichos indicadores nos servirían para valorar la predisposición de un Estado a cooperar con el resto de actores de la escena internacional. El proceso de integración en materia de seguridad y defensa que se está materializando progresivamente, podrá ir limando los recelos y podrá ir fomentando el consenso en cuanto a las creencias y expectativas compartidas se refiere.

En relación al impacto que la CEP pueda tener sobre el proceso de integración europea tenemos que destacar el debate que ha surgido en relación al carácter inclusivo o exclusivo de dicho mecanismo, ya que hay autores que se decantan por concebir a esta modalidad de cooperación como un elemento inclusivo mientras que otros apuestan más bien por concebirlo como un mecanismo meramente exclusivo.

Una opinión bastante compartida en relación a este mecanismo consiste en concebir a la CEP como un concepto inclusivo, previendo la posibilidad de que participen cuantos más

\footnotetext{
${ }^{34}$ Biscop, Sven y Coelmont, Jo: "Permanent Structured Cooperation in Defence of the Obvious", Security Policy Brief $\mathrm{n}^{\circ} 11$, EGMONT, Royal Institute for International Relations (junio 2010), en http://aei.pitt.edu/14432/1/SPB-11_PSCD_II.pdf.

${ }^{35}$ Keohane, Robert O.: "Transgovernmental Relations and International Organizations", World Politics, vol. 27, $\mathrm{n}^{\mathrm{o}} 1$ (October 1974), p.51.

${ }^{36}$ Grieco, Joseph: "Realist Theory and the Problem of International Cooperation: Analysis with an Amended Prisoner's Dilemma Model”, The Journal of Politics, vol. 50, n³ (agosto 1988), pp.610-611.
} 
Estados miembros de la UE sea posible. De hecho, podríamos concebir a la CEP como un mecanismo en materia de defensa que lo que pretende es animar a todos los países miembros de la UE a que contribuyan y participen más en todos los procesos concernientes a la mejora de la capacitación y proyección de sus respectivas fuerzas militares.

Por el contrario, la concepción exclusivista argumenta que el grupo central de Estados de la UE entre los que podemos destacar a Francia, Reino Unido, Alemania, España, Italia y Polonia, no tendrían en cuenta el potencial de los Estados miembros más pequeños, minando de esta manera el espíritu del propio proceso de integración europea.

Del mismo modo también argumentan que la exclusividad podría amenazar a la ayuda pública de la PCSD que los Estados miembros no participantes en el mecanismo llevan a cabo. Argumentan que este mecanismo no puede llevar a ninguna mejora, y que no va a permitir a la UE conseguir uno de sus objetivos prioritarios en relación a la PCSD, como es el de materializar el aumento de la cooperación entre los diferentes Estados miembros. Se basan sobre todo en el argumento de que sería un desafío técnico el conseguir garantizar la participación de los 27 Estados miembros que participan en la PCSD. Además, los que apuestan por el enfoque exclusivista consideran que sería crucial analizar cuál es la motivación de los Estados miembros de la UE para ensamblar la cooperación estructurada permanente. De todas formas y a pesar de todos estos factores, la voluntad política limitada de algunos Estados miembros de la UE se sigue presentando como el principal escollo en relación a este asunto.

A pesar de todos estos hándicaps lo que sí parece claro es que un acercamiento inclusivo permitiría mayores sinergias y efectos de la escala y del resultado en valor agregado para la UE. Por lo tanto, el caso ideal sería integrar con el tiempo a los 27 Estados miembros activos en PCSD en dicho mecanismo ${ }^{37}$. Sea como fuere, el debate está servido y guarda mucha relación con las distintas concepciones que existen en el seno de la UE sobre lo que es Europa, y sobre lo que ésta debe hacer en la escena internacional.

La pregunta que se plantea ahora es determinar bajo qué circunstancias y con qué Estados miembros de la UE se prevé la utilización de esta modalidad de cooperación. Para ello, el tema del análisis de las ganancias relativas ${ }^{38}$ y absolutas cobra especial importancia en contextos donde se percibe la interacción asimétrica entre Estados de diferente tamaño. De hecho, no podemos olvidar que en el ámbito de la cooperación internacional cuando se registra un aumento desproporcionado de las ganancias por parte de un actor determinado dicho aumento es percibido por el resto de actores como una amenaza potencial. Por ese motivo, y aunque se presente complicado distinguir claramente las ganancias relativas de las absolutas, el análisis de las mismas se presenta de vital importancia para poder comprender las dinámicas de cooperación que se materialicen en el seno de las instituciones. Entre otras razones porque:

1. Los Estados tienen en cuenta y se preocupan por valorar las ganancias relativas propias y la del resto de actores para extender sus objetivos relacionados con factores como el prestigio, el estatus, y las preferencias de actuación.

\footnotetext{
${ }^{37}$ Entre los 27 Estados incluimos a Croacia que entró a formar parte del proyecto de la UE el pasado 1 de julio de 2013. Seguimos sin contar con Dinamarca, ya que este país no participa en la Política Común de Seguridad y Defensa (PCSD).

${ }^{38}$ Grieco, Joseph; Powel, Robert y Snidal, Duncan: "The Relative-Gains Problem for International Cooperation", The American Political Science Review, vol. 87, no 3 (septiembre 1993), pp. 727-743.
} 
2. Las ganancias relativas pueden servir para fijar con más precisión los objetivos que tienen los actores en relación al aumento de sus correspondientes cuotas de poder.

3. Gracias al análisis de dichas ganancias estaremos en condiciones de comprender adecuadamente las relaciones que en el seno de las instituciones se materializan entre los diferentes actores que la conforman ${ }^{39}$.

Además, y como veremos más adelante, lo importante es que tenemos que tener en cuenta que si dicha cooperación se materializa en el seno de un contexto institucional, se podrá evitar el riesgo de que uno de los actores participantes decida unilateralmente cambiar los términos de dicha cooperación.

Por tanto, el peligro estribaría en comprobar y saber qué es lo que sucederia si los Estados decidieran no utilizar los medios y recursos que ofrece el mecanismo de la $\mathrm{CEP}^{40}$. En relación a esto último podríamos traer a colación lo que ocurre con los denominados Battlegroups que no han sido empleados hasta el día de hoy por razones estrictamente políticas más que operativas ${ }^{41}$. De hecho la UE no cuenta con una política compartida en relación a cómo usar los Battlegroups ${ }^{42}$. Para evitar que esto se vuelva a repetir la UE debería centrarse en facilitar la convergencia política y los procesos decisorios con vistas a que el desarrollo de las capacidades militares se lleve a cabo de manera más racional y eficiente.

Hay que destacar que cuando estas unidades de combate aparecieron, lo hicieron con el doble objetivo de, por un lado, que los Estados participantes llevaran a cabo una transformación de sus correspondientes fuerzas armadas (FFAA) para que estas mejorasen en cuanto a su preparación y puesta en liza se refiere, en operaciones de soft security. Todo ello a través de una mejora en cuanto a la coordinación e integración de las estructuras de las distintas FFAA se refiere. Por otro, con el objetivo de proveer a la UE de una cierta autonomía operativa, ya que seguía y sigue dependiendo en exceso de la OTAN $^{43}$. Lo interesante en este asunto es destacar el hecho de que las tres principales potencias de la UE como son Alemania, Francia y Reino Unido decidieran apostar por la creación de este tipo de unidades. Este hecho se interpretó como un nuevo intento por agrupar sinergias de cooperación en el seno de la PCSD.

\footnotetext{
39 Snidal, Duncan: "Relative Gains and the Pattern of International Cooperation", The American Political Review, vol. 85, n 3 (septiembre 1991), p.704.

${ }^{40}$ Biscop, Sven y Algieri, Franco: "The Lisbon Treaty and ESDP. Transformation and Integration", EGMONT, Royal Institute for International Relations (junio 2008), en http://aei.pitt.edu/8966/1/ep24.pdf.

${ }^{41}$ En relación al nulo uso de estas unidades tácticas podríamos destacar en primer lugar, la exigencia de la regla de la unanimidad a la hora tomar la decisión de poner en práctica algún Battlegroup. En segundo lugar, la falta de voluntad mostrada por algunos países en relación al uso de la fuerza, y por último, el debate entre europeístas y atlantistas. Estos últimos considerarían que los Battlegroups no son necesarios, ya que la OTAN contaría ya con este tipo de fuerzas de reacción rápida.

42 Santopinto, Federico y Price, Megan (ed.) (2013): National visions of EU Defence Policy. Common denominators and misunderstandings, Bruselas, Centre for European Policy Studies (CEPS), en http://www.ceps.be/book/national-visions-eu-defence-policy-common-denominators-and-misunderstandings.

${ }^{43}$ Major, Claudia y Molling, Christian: "EU Battlegroups: What contribution to European Defence?. Progress and Prospects of European Rapid Response Forces", SWP Research Paper, $\mathrm{n}^{\circ}$ 8, German Institute for International and Security Affairs (junio 2011), en http://www.swp-berlin.org/fileadmin/contents/products/research_papers/2011_RP08_mjr_mlg_ks.pdf.
} 
En todo caso la aparición de este mecanismo tenemos que contextualizarla dentro de la diatriba existente entre solidaridad y efectividad ${ }^{44}$. Por tanto, la evolución de dicho mecanismo estará posiblemente sujeta a la concepción que sobre Europa predomine dentro del proyecto comunitario. Además, tenemos que recordar que sin la contribución de este tipo de mecanismos cualquier avance en materia de PCSD se podría ver ralentizado, ya que la regla de la unanimidad parece un obstáculo bastante difícil de superar. Es mejor que se adopten este tipo de mecanismos caracterizados por su flexibilidad, y que respeten la soberanía estatal para que las reticencias estatales a ceder soberanía no aumenten, y puedan dar al traste con la lógica comunitaria de ir aumentando los niveles de integración en todos los ámbitos políticos inclusive el que tiene que ver con la seguridad y defensa.

Esta modalidad de cooperación podría presentarse como una etapa intermediaria a la integración adicional entre los socios que se muestran más entusiastas en relación al proyecto comunitario y aquellos de reciente ingreso, y que cuentan con menos peso. Lo importante es que este mecanismo representa un espacio abierto de negociación y creatividad en relación a uno de los elementos más problemáticos del proceso de integración europea ${ }^{45}$.

En este sentido, el espacio abierto para la negociación que representa este mecanismo cuadraría bastante bien con el enfoque que presenta el mecanismo de la CEP. Nos encontramos ante un enfoque Top-Down, donde las iniciativas de desarrollo de dicho mecanismo se presentan abiertas para todos los Estados miembros de la UE, independientemente de que en una etapa inicial dichas iniciativas sean implementadas y lideradas por un grupo pionero de Estados.

De hecho, y a tenor de lo que indica el artículo 42.6 del Tratado de Lisboa ${ }^{46}$ podemos decantarnos por concebir a la CEP como una modalidad de cooperación restringida puesto que dicha cooperación está abierta sólo a aquellos Estados miembros :

\section{Que cumplan los "criterios más elevados de capacidades militares"}

2. Que hayan suscrito "compromisos más vinculantes" en la materia para realizar las misiones más exigentes.

Independientemente de que se considere a la CEP como una modalidad de cooperación restringida, no debemos olvidar que el objetivo que se marcaron los decisores comunitarios con el empleo de este tipo de mecanismos de cooperación flexible consistía en garantizar el triunfo de una especie de sinergia institucional que fuese contagiosa. Como sabemos en el seno de la propia UE, existen distintas visiones del papel que Europa puede y debe jugar, y estas modalidades de cooperación flexible facilitan la creación de complicidades y sinergias en torno a una serie de prioridades para la política del conjunto de la Unión. Es decir, lo que se pretende es que se impulse en una primera fase, y de manera bilateral la toma de decisiones

\footnotetext{
${ }^{44}$ Van Eekelen, Willem F. y Kurpas, Sebastian: "The evolution of flexible integration in European Defence Policy: is permanent structured cooperation a leap forward for the common security and defence policy?", CEPS Working Document, n 296 (junio 2008), en http://aei.pitt.edu/9316/2/9316.pdf.

${ }^{45}$ Angelet, Bruno y Vrailas, Ioannis: "European Defence in the wake of the Lisbon Treaty", EGMONT, Royal Institute for International Relations (mayo 2008), en http://www.egmontinstitute.be/paperegm/ep.21.pdf.

${ }^{46}$ Como se desprende del propio artículo 42.6 del Tratado de Lisboa, la Cooperación Estructurada Permanente podría definirse como un mecanismo de cooperación en materia de defensa previsto en el Tratado de Lisboa, a través del cual los Estados pueden avanzar de forma rápida y cooperar de forma más estrecha en el desarrollo de sus capacidades militares.
} 
en ámbitos concretos para posteriormente, e invitando a otros Estados a unirse, reproducir el debate en otros foros con repercusiones en política internacional. Por tanto, las iniciativas de cooperación flexibles aunque en un principio sólo involucren a un número determinado de Estados, con el tiempo son susceptibles de transformarse en cuestiones multilaterales.

\section{La Unión Europea en cuanto "Comunidad de Seguridad"}

El proceso de integración europea en materia de seguridad, y defensa, se ha ido desarrollando progresiva y paulatinamente hasta el punto de que podemos plantearnos, si asistimos o no ante una auténtica "comunidad de seguridad". Esta pregunta es importante porque nos ayudará a calibrar en qué fase del proceso de integración regional se encuentra la UE en materia de seguridad y defensa.

Estas comunidades de seguridad comienzan cuando los Estados buscan relaciones más estrechas, reconociendo que la cooperación en materia económica, y en materia de seguridad y defensa van más allá de sus intereses particulares. Además, el aumento de la identificación y la confianza mutuas comportan la desaparición de la percepción de los otros como posibles amenazas. Por tanto, las comunidades de seguridad en su fase más elevada darían cabida y cobertura al mecanismo de la CEP, y a la otra modalidad de cooperación presentada por el Tratado de Lisboa como es el de la cooperación reforzada.

Hay que destacar, que dicha comunidad se erigiría, junto al elemento de la paz perpetua de inspiración kantiana, en uno de los dos conceptos de seguridad que la UE ha abrazado hasta ahora ${ }^{47}$. De hecho, la paz ha sido, y sigue siendo, la piedra angular sobre la que pivota el proyecto de integración regional que representa la $\mathrm{UE}^{48}$.

El concepto de comunidad de seguridad fue presentado por Karl Deutsch en 1957, con vistas al establecimiento de estructuras colectivas que generasen la confianza suficiente, y necesaria para evitar el posible estallido de conflictos armados y/o guerras. Este autor concibe a la "comunidad de seguridad" 49 , como un grupo de pueblos integrados por un sentido de comunidad. Dicho sentimiento se presentaría como la creencia generalizada existente dentro de dicho grupo en relación a que los problemas comunes existentes podrían, y debían de ser resueltos a través de procesos de cambio pacíficos. Dichos procedimientos de cambio pacíficos conformarían una especie de procedimientos institucionalizados, donde el uso de la fuerza no tendría cabida.

De todas formas, tenemos que tener en cuenta como manifestó uno de los pioneros de los estudios sobre integración, Karl Deutsch, que una cosa es la integración, y otra cosa bien distinta, es la fusión concebida como unificación política, puesto que ésta comporta unos niveles de convergencia y de unión difíciles de conseguir ${ }^{50}$.

\footnotetext{
${ }^{47}$ Moustakis, Fotios y Sheehan, Michael: "Democratic Peace and the European Security Community: The Paradox of Greece and Turkey", Mediterranean Quarterly, vol.13, n¹ (invierno 2002), p.70.

${ }^{48} \mathrm{La}$ "Paz" concebida como una paz democrática que podría ser justificada e interpretada en función de razones normativas (culturales), y de razones institucionales (estructurales).

${ }^{49}$ Deutsch, Karl W (1957): Political Community, and the North Atlantic Area: International Organization in the light of historical experience, Nueva York, Princeton University Press, p.5.

${ }^{50}$ Merrit, Richard L. y Russet, Bruce M. (1981): From National Development to Global Community, Essays in Honor of Karl W. Deutsch, Londres, George Allen and Unwin Ltd, p. 8.
} 
Dicha definición de "comunidad de seguridad" fue ampliada, y en parte corregida, por Adler y Barnett. Para estos autores, la "Comunidad de Seguridad", consistiría en una región transnacional compuesta por Estados soberanos en los que sus correspondientes pueblos comparten una cierta dependencia en relación a la expectativa de registrar cualquier cambio, y de solventar cualquier disputa que pudiera surgir entre ellos de forma pacífica ${ }^{51}$. Lo importante es que dichos autores destacan los elementos cognitivos que se centran en las prácticas compartidas, y en la identificación de imágenes y percepciones comunes ${ }^{52}$. Por lo tanto, la identidad se presenta como uno de los elementos esenciales en dicha región cognitiva.

En este sentido, y para poder comprender mejor dicha armonización de intereses y valores, es importante destacar lo que Alexander Wendt establece como estructuras intersubjetivas. Dichas estructuras consisten en el hecho, de que los Estados comparten comprensiones, expectativas y conocimientos sociales en relación a las instituciones internacionales y a las amenazas complejas a las que deben hacer frente ${ }^{53}$.

Estas estructuras intersubjetivas descansarían en el hecho de que:

1. Los Estados a menudo comparten interpretaciones de sus desarrollos.

2. Los Estados dependen los unos de los otros, como mínimo en parte, por alguna de esas interpretaciones.

3. La interacción estratégica de los Estados contribuye más al hecho de que compartan sus percepciones.

En este sentido, las normas y valores son compartidos, y consensuados por los Estados miembros. Al compartir dichas normas y valores, lo que sucede es que se otorga a dichas comunidades de seguridad, el privilegio de marcar la pauta del comportamiento de los diferentes Estados participantes ${ }^{54}$. El hecho de que se establezca finalmente una especie de seguridad colectiva, indicaría que los Estados participantes compartirían una identidad común. Identidad que por cierto, no sería fija e inamovible, sino más bien todo lo contrario. De hecho, las identidades de los Estados serían variables, ya que dependerían del contexto histórico, cultural, político y social ${ }^{55}$. Por tanto, las comunidades de seguridad se podrían presentar como formas de identidad colectiva. Dichas identidades colectivas se configurarían en torno al principio de diferenciación existente en relación al resto de comunidades ${ }^{56}$.

\footnotetext{
${ }^{51}$ Adler y Barnett, op. cit., pp. 30-34.

${ }^{52}$ Krause, Keith: "Critical Theory and Security Studies", Cooperation and Conflict, vol.33, no 3 (1998) p. 315.

${ }^{53}$ Wendt, Alexander: "Collective Identity Formation and the International State", American Political Science Review, vol. 88, n’ 2 (junio 1994), p.389.

54 Adler, Emanuel: "Seizing the Middle Ground: Constructivism in World Politics", European Journal of International Relations, vol.3, $\mathrm{n}^{\circ} 3$ (1997), pp. 264-265.

${ }^{55}$ Hopf, Ted: "The Promise of Constructivism in International Relations Theory", International Security, vol.23, $\mathrm{n}^{\mathrm{o}} 1$ (verano 1998), p.176.

${ }^{56}$ Ulusoy, Hasan: "Reivisiting Security Communities after the Cold War: The Constructivist perspective", SAM PAPERS, Center for Strategic Research, Ministry of Foreign Affairs, Republic of Turkey (septiembre/noviembre 2003) en http://sam.gov.tr/revisiting-security-communities-after-the-cold-war-the-constructivist-perspective/.
} 
Después de presentar los elementos fundamentales sobre los que descansaría la comunidad de seguridad, y de señalar los elementos que la conforman", podríamos señalar la relación existente entre las comunidades de seguridad y los regímenes internacionales. La idea de los regímenes internacionalesfue tratada en la década de los 80 por autores como Stephen D. Krasner, Robert O. Keohane, Ernst Haas, y Hedley Bull. Dichos regímenes podrían ser definidos como el conjunto de principios, normas, reglas, y procedimientos de toma de decisiones alrededor de las cuales las expectativas de los diferentes actores convergen en una determinada área de las relaciones internacionales ${ }^{57}$. Esto es precisamente lo que presentan las denominadas comunidades de seguridad.

Los desarrollos registrados a nivel institucional y normativo muestran, en parte, como en todo este proceso, se registraría un nivel de convergencia interesante en cuanto a valores, principios, e instituciones relacionadas con la PCSD. Todo este desarrollo ha ido en consonancia con el tipo de poder que representa la UE hoy en día. De hecho, la UE se presenta como un poder normativo ${ }^{58}$, que ha influido notablemente en la construcción de la identidad europea Por lo tanto, el desarrollo normativo, y la creación de nuevas instituciones han marcado la pauta de crecimiento del proceso de integración en materia de seguridad y defensa, al incidir favorablemente en la conformación de la identidad europea en materia de seguridad y defensa.

Este fortalecimiento interno le ha permitido dar un paso hacia adelante en relación a la responsabilidad internacional que la UE tiene que asumir en relación a la gestión de los asuntos globales. La UE, que ha sido presentada como una potencia civil, en la actualidad tiene la obligación imperiosa de dotarse de aquellas capacidades militares de las que adolece con vistas a convertirse a un proveedor de seguridad, asumiendo responsabilidades en la ordenación del sistema internacional, en función de los procesos de reestructuración a los que estamos asistiendo con el auge de los Estados emergentes. Hubo autores que pensaron que la UE no es sólo un proyecto exclusivamente europeo, sino que se presenta como una parte de un esfuerzo global para coordinar, y reconciliar las diferencias humanas en el actual contexto de la globalización ${ }^{59}$. Pero curiosamente la UE se decantó por una concepción del poder posmoderno donde la búsqueda de la paz y la estabilidad se convirtieron en sus principales objetivos a materializar. La UE se presentaba como un proyecto de paz de clara inspiración kantiana $^{60}$. Kant apostaba por una federación de la paz consistente en una federación entre Estados que garantizasen el respeto y estabilidad entre ellos de manera que se redujera o eliminase de una vez por todas la opción de la guerra.

Ciertamente no se puede olvidar que la búsqueda de la paz ha sido el principal motivo de arranque y de desarrollo del proceso de integración europea. En un primer momento, el proyecto europeo lo que pretendió fue la consecución de una paz estructural que hiciera

\footnotetext{
57 Krasner Stephen D.: "Structural causes and regimen consequences: regimes as intervening variables", International Organization, vol. 36, n 2 (primavera 1982), p.186.

${ }^{58}$ Manners, Ian: "The European Union as a Normative Power: A response to Thomas Diez", Millennium, vol. $35, \mathrm{n}^{\circ} 1$ (2006), pp. 167-180.

${ }^{59}$ Kristeva, Julia (2000): Europe divided: Politics, Ethics, Religion, in Crisis of the European Subject, Nueva York, Other Press, pp.114-115.

${ }^{60}$ Kant, Emmanuel (2002): La Paz Perpetua, Madrid, Tecnos, p.14; En este contexto se explica el nombramiento por Javier Solana de Robert Cooper, un kantiano, como Director-General for External and Politico-Military Affairs, y el patrocinio de otras iniciativas en esta línea, como la financiación de estudios e informes sobre la doctrina de seguridad humana para Europa. Todo esto, a muy pocos años vista, no puede dejar de sorprender. Es un ejemplo más de la falta de visión de los dirigentes europeos.
} 
imposible e impensable la guerra entre países europeos ${ }^{61}$. El triunfo de este proyecto ha convertido a la UE en uno modelo de integración regional a seguir donde la UE contaría con un tipo de poder blando (Soft Power) ${ }^{62}$. Dicho tipo de poder consistiría en la habilidad de influir y moldear las preferencias de los otros actores. Todo ello incidiría positivamente en cuanto a los niveles de atracción del proceso de integración regional que representa se refiere.

De hecho, hay autores que llegaron a concebir al proyecto de la UE como un proyecto de paz perpetua ${ }^{63}$ y otros que consideraron que el proyecto de la UE no podía ser explicado sólo en términos materiales puesto que el tipo de poder que ejerce es más bien de tipo normativo $^{64}$. Su comportamiento se vería condicionado por sus principios y valores..

Además, podríamos hacer referencia al hecho de que a la UE se la catalogó dentro de lo que se ha venido denominando, como "Small Power" ". De hecho, seguiría cumpliendo los principales factores ${ }^{66}$ que demanda la naturaleza propia de este tipo de poder, ya que manifiesta desde un punto de vista estratégico una cierta dependencia. Dicha dependencia sería probada a través de la relación operativa y estratégica que presenta en relación a la OTAN. En segundo lugar, se registraría una cierta geometría variable en cuanto a la ejecución de sus poderes se refiere. En tercer lugar, la UE apostaría por el fortalecimiento del derecho internacional. Por último, tenemos que indicar que la UE ha presentado una naturaleza claramente defensiva. De hecho, la UE no ha apostado por la coerción, sino más bien por las soluciones multilaterales, considerándolas suficientes. Por lo tanto, el tipo de poder del que ha hecho gala la UE, desde esta perspectiva, podría ser usado como un factor más que explique la importancia y la efectividad de la comunidad de seguridad que representa.

La respuesta a la pregunta que planteamos anteriormente en relación a la finalidad de la PCSD es fundamental para poder entender el grado de integración que se ha registrado en materia de seguridad y defensa hasta el momento. La UE representa a día de hoy una comunidad de seguridad bastante peculiar que fomenta y facilita las dinámicas del proceso de integración regional, pero que tiene imperiosamente que incrementar sus capacidades militares para poder contribuir a la reconfiguración del sistema internacional, dado que su principal aliado, los Estados Unidos, está en un proceso de claro desfallecimiento relativo. En parte, el desarrollo de la PCSD podría fundamentarse sobre la opinión general extendida que considera que la UE siempre debe de ir dando pasos hacia adelante, adaptándose a nuevas situaciones. Todo lo que no sea ir hacia adelante se podría interpretar como un claro retroceso en cuanto a su dinámica de integración se refiere. Por ello, y como veremos a continuación tenemos que prestar atención al potencial dinamizador que presenta la CEP en relación a la PCSD.

\footnotetext{
${ }^{61}$ Zilibi, Igor: "Moldeando la paz estructural. Proceso de integración europeo y resolución de conflictos", Working Papers/Munduan, Cooperación Internacional Descentralizada (2005), p.16.

${ }^{62}$ Keohane, Robert O.: "Accountability and the Abuse of Power in World Politics", American Political Science Review, vol. 99, no 1 (febrero 2005), p. 37.

${ }^{63}$ Glasius, Marlies y Kaldor, Mary: "Individuals first: the Human Strategic for the European Union", International Politik und gesellschaft (2005), en http://library.fes.de/pdf-files/id/ipg/02693.pdf.

${ }^{64}$ Manners, Ian: "Normative Power Europe: A Contradiction in Terms?", Journal of Common Market Studies, vol.40, n² (2002), pp. 235-258.

${ }^{65}$ Toje, Asle: “The European Union as a Small Power”, Journal of Common Market Studies, vol. 49, n 1 (2011), pp.43-60.

${ }^{66}$ Ibid., pp. 47-48.
} 


\section{Análisis del impacto de la CEP sobre la "Comunidad de Seguridad Europea"}

El mecanismo de la CEP se presenta con un potencial bastante considerable en relación a los futuros desarrollos que la PCSD pueda ir registrando. La cuestión ahora es tratar de analizar el impacto que dicho mecanismo de defensa pudiera presentar en relación a la consolidación y desarrollo de la UE como comunidad de seguridad. Para averiguar esto último, podríamos analizar los tres factores que Adler y Barnett ${ }^{67}$, presentan como indispensables para que podamos hablar de una comunidad de seguridad.

En este sentido, dicha posibilidad se basaría en primer lugar, en comprobar si en el seno de la UE se registra, aunque sea levemente, una identidad común en el ámbito de la PCSD. En relación a esto último habría que añadir el hecho de que compartir las mismas amenazas, y objetivos en el contexto internacional, obliga a la UE a dotarse de un marco estratégico, más o menos, definido. Dicho marco estratégico incluiría elementos de una identidad común y compartida.

En relación a este primer punto, deberíamos indicar que la CEP, sí que influiría positivamente en la capacitación y por tanto, en la delimitación de las misiones internacionales que la UE pudiese llevar a cabo. La cooperación se iniciaría en función de que se registre la "securitización" de dichas amenazas por parte de un grupo de Estados miembros de la UE.

En segundo lugar, tendríamos que hacer referencia al hecho de que existan valores y normas compartidas por todos los Estados miembros de la UE. Como destacaba el profesor Deutsch, los Estados en el momento en que empiezan a formar parte de una alianza/comunidad, comienzan a prestar atención a factores distintos a los que prestaban atención cuando no formaban parte de dicha alianza/comunidad ${ }^{68}$. De este modo, podríamos considerar la influencia que dicha comunidad de seguridad podría ejercer sobre los valores, y principios de los Estados participantes en materia de seguridad y defensa.

En este punto, la CEP gozaría de un protagonismo considerable, ya que se presenta como la plataforma ideal para la realización de proyectos de capacitación, acciones, misiones internacionales, etc..., que se presenten con la etiqueta de comunes. Esto obviamente podría contribuir al reforzamiento del sentimiento de pertenencia a una determinada comunidad. De hecho, se podría erigir como una plataforma de cooperación donde se registre la persuasión y el proceso de socialización de manera que se vaya generando una identidad común en materia de seguridad y defensa.

El tercer factor, haría hincapié sobre el tema de la responsabilidad mutua. Aquí cobraría importancia, una de las novedades aportadas por el Tratado de Lisboa, como es el de la cláusula de solidaridad. Esta idea de solidaridad cuadraría perfectamente en la dinámica de cooperación interestatal. Dicha dinámica de cooperación entre Estados que generaría una especie de protección mutua, se presentaría a su vez, como uno de los factores determinantes en la confección de las comunidades de seguridad. De hecho, estas se basarían en la existencia de una serie de demandas subjetivas de seguridad ${ }^{69}$. Dichas demandas se centrarían por un

\footnotetext{
${ }^{67}$ Adler y Barnett, op. cit., p.40.

${ }^{68}$ Deutsch, Karl W. y Singer, David J.: "Multipolar Power Systems and International Stability", World Politics, vol. 16, nº 3 (abril 1964), p. 397.

${ }^{69}$ Jervis, Robert: "Cooperation under the Security Dilemma", World Politics, vol. 30, Issue 2 (enero 1978), p.174.
} 
lado, en explicar cuánto estarían dispuestos a pagar los Estados por garantizar su propia seguridad, y por otro lado, en determinar si existe una percepción común en cuanto a las amenazas se refiere. El formar parte de la UE conlleva una serie de obligaciones pero al mismo tiempo, incluye una serie de prerrogativas importantes. El hecho de pertenecer a un determinado colectivo, como es en este caso la UE, contribuye a que poco a poco, se vaya gestando una identidad de pertenencia. Dicha identidad podría ir marcando las pautas de cambio en cuanto a nuestros valores y principios se refiere.

El mecanismo de cooperación en materia de defensa que representa la CEP, no se presenta con el objetivo principal de transferir soberanía sobre el planeamiento de defensa al nivel de la UE, sino que lo que pretende es ayudar a los Estados miembros de la UE a recuperar los niveles de soberanía erosionados como consecuencia de la crisis económica $\operatorname{actual}^{70}$. Los Estados no pueden hacer frente a las nuevas demandas relacionadas con la seguridad y defensa, que presenta el panorama actual. Por este motivo, la cooperación se presenta como uno de los mejores medios para poder superar esta situación.

Entre los objetivos estratégicos que se marca esta modalidad de cooperación podríamos destacar los siguientes ${ }^{71}$ :

1. Creación de capacidades militares.

2. Asegurar compromisos operacionales.

3. Garantizar la inversión de los gobiernos en defensa.

Tendremos que tener en cuenta estos tres objetivos estratégicos para poder comprender los compromisos a los que puedan llegar los Estados que decidan participar en este mecanismo. Entre esta serie de compromisos podríamos destacar los siguientes ${ }^{72}$ :

1. Alcanzar los niveles de gasto en inversión en equipos de defensa acordados, revisándolos periódicamente.

2. Convergencia en los instrumentos de defensa especializándolos si fuera necesario, y fomentar la cooperación en los ámbitos de formación y logística.

3. Reforzar la disponibilidad, interoperabilidad, flexibilidad y la capacidad de despliegue de fuerzas.

4. Cooperar para garantizar que se superan las insuficiencias que se observen en el marco del mecanismo de desarrollo de capacidades.

\footnotetext{
${ }^{70}$ Biscop, Sven y Coelmont, Jo: "Pooling and Sharing: From Slow March to Quick March", Security Policy Brief $\mathrm{n}^{\circ} 23$, EGMONT, Royal Institute for International Relations (mayo 2011), en http://www.europarl.europa.eu/meetdocs/2009_2014/documents/sede/dv/sede140611spbpoolingsharing /sede14 0611 spbpoolingsharing en.pdf.

${ }^{71}$ Artículo 1 del Protocolo ${ }^{\circ} 10$ sobre la Cooperación Estructurada Permanente establecida por el artículo 42 del Tratado de la Unión Europea.

${ }^{72}$ Artículo 2 del Protocolo $n^{\circ} 10$ sobre la Cooperación Estructurada Permanente establecida por el artículo 42 del Tratado de la Unión Europea.
} 
5. Participación (en caso necesario) en el desarrollo de programas comunes o europeos de equipos de gran envergadura en el marco de la Agencia Europea de Defensa (EDA).

La CEP podría facilitar una mejor comprensión de los temas que afectan a la defensa común entre los niveles políticos y militares, de manera que se consiga una mayor coherencia en ambos niveles de actuación. De hecho, no únicamente en lo que respecta a la definición de objetivos, sino que nos permitiría asegurar la correcta implementación de los objetivos políticos generales que persigue la UE. En este sentido, el hecho de que se adquieran capacidades militares conjuntas no significa que aumente directamente la interoperabilidad común, la logística común, entrenamientos, formación, doctrina, etc... ${ }^{73}$, por lo que tendremos que aprovechar este mecanismo para ir profundizando en todas estas áreas de intervención sin dejar de destacar que la adquisición conjunta se presenta a todas luces como uno de los principales pasos a dar en pos de la consecución de la adecuada interoperabilidad de las fuerzas al servicio de la UE. En relación a esto último tendremos que seguir muy de cerca la labor que desempeña la OTAN a través de su agencia de estandarización (NATO Standardization Agency).

Sea como fuere, la necesidad de cooperar en esta materia se presenta, a todas luces, necesaria puesto que las ventajas que presenta son mayores que los esfuerzos que implica el participar en el seno de dicho mecanismo. Entre otras ventajas podríamos señalar las siguientes:

1. Disponer de capacidades a un precio menor que si se adquirieran a nivel nacional. Esto obviamente ofrece unas ventajas comparativas difíciles de negar debido al alto coste que presenta la adquisición de material de defensa.

2. Mejorar la interoperabilidad de las fuerzas multinacionales. Esta modalidad de cooperación garantiza la realización de ejercicios conjuntos susceptibles de contribuir al conocimiento de otras FFAA, así como a la mejora de la interoperabilidad de las diferentes FFAA que formen parte de dicho proceso de cooperación.

3. Obtener un mayor crédito político al ser percibidos como socios constructivos. Desde un punto de vista puramente político el poder participar en estos procesos de cooperación garantiza a los países un rédito político al presentarlos ante la opinión pública europea e internacional como miembros del club de los abanderados del proceso de integración regional que representa la UE.

4. Mantener y promover la tecnología e industria de la defensa europea. Sin la materialización de dicha cooperación en materia de defensa, la EDA no tendría razón de ser. Por tanto la CEP se presenta como una plataforma ideal para fomentar la funcionalidad de la EDA.

Otra cuestión a destacar sobre la CEP en materia de defensa, es que se presenta como un mecanismo diferente al que representa la cooperación reforzada. Dichas diferencias se centran sobre todo en cuanto al alcance e intensidad que presentan. De hecho, este mecanismo se ha establecido con vistas a conseguir dos objetivos prioritarios y específicos relacionados con el

${ }^{73}$ Biscop y Algieri, op. cit., p.12. 
ámbito propiamente militar, y con el ámbito político. De esta manera, y si nos atenemos a los objetivos estratégicos de la UE en relación a dicho mecanismo, lo que persigue es por un lado, la creación de capacidades militares adecuadas, y por otro, el establecimiento de comisiones permanentes que garanticen la participación, y la interrelación entre todos sus miembros. De esta manera se pondrían las bases para la consolidación y mantenimiento de la comunidad de seguridad que representa.

Además, tenemos que tener en cuenta, que la CEP es mucho más flexible que la otra modalidad de cooperación puesto que con el nuevo Tratado, no hay un umbral fijo para los nuevos Estados que participen en dicho mecanismo. Junto a esto último tenemos que señalar que los criterios mencionados en cuanto a la admisión, parecen no excluir a nadie gracias al establecimiento del voto por mayoría cualificada. Voto que también se hace extensible para el caso de que se solicite la suspensión de la participación de algún Estado participante por no cumplir con los propósitos asumidos ${ }^{74}$. Para el resto de las decisiones relacionadas con la ejecución de este mecanismo tendremos que ajustarnos a la regla de la unanimidad.

En este proceso, lo importante es analizar qué es lo que ocurre a nivel comunitario, y de qué manera la CEP afecta al sentimiento de pertenencia e identidad propiamente europea a través de los procesos de persuasión y socialización que se registren en el seno de las plataformas de cooperacion. Por ello, deberíamos tener en consideración el resultado de todas las dinámicas de cooperación y colaboración, que se registren en el ámbito de la seguridad y defensa europea como consecuencia de la aplicación del mecanismo de defensa que representa la CEP.

\section{Conclusiones}

En general la cooperación en materia de defensa no se fomenta demasiado cuando el contexto se caracteriza por la austeridad y un nivel de amenaza bajo. Para el caso de la UE es más bien todo lo contrario, ya que parece estar dispuesta a superar las diferencias nacionales, y a mejorar el nivel de confianza entre sus Estados miembros con vistas a conseguir la materialización de una auténtica defensa común europea. Dicho logro supondría el espaldarazo definitivo para el proceso de integración europea. Que mejor prueba de integración y de convergencia que el compartir recursos, medios, doctrina, formación, etc..., en materia de seguridad y defensa, a otrora los sectores más impermeables e inaccesibles para dicho proceso de integración.

La CEP se presenta como un elemento clave para ver si la UE se va a consolidar como una auténtica comunidad de seguridad de manera que se vayan superando las dinámicas competitivas entre las grandes potencias europeas, así como las tradicionales idiosincrasias que limitan la eficacia de la UE en el plano exterior.

Este mecanismo de defensa al servicio de la UE tendrá más posibilidades de triunfo si sus Estados miembros apuestan por reforzar la defensa colectiva y la asistencia mutua. En este sentido cabría indicar que los desarrollos que se registren en el seno de la PCSD gracias a la aportación del mecanismo de la CEP no implicarían en un primer momento un apoyo directo para el proceso de integración, aunque sí que podrían ser percibidos como un paso cualitativo

${ }^{74}$ Angelet et al., op. cit., p. 33. 
importante hacia la unión política que, a la postre, beneficiaría el proceso de integración europea en materia de seguridad y defensa.

En todo este proceso tendremos que tener en cuenta la importancia que presenta el factor de la confianza mutua. Elemento clave para la consolidación y viabilidad de las comunidades de seguridad. En relación al factor de la confianza mutua deberíamos de destacar el interés manifestado en el Consejo Europeo del 19 y 20 de diciembre de 2013, por mejorar el nivel de transparencia en el ámbito de la seguridad y defensa.

En cuanto al peligro que podría comportar el carácter exclusivista del mecanismo de la CEP podríamos indicar que el proceso liderado por un grupo pionero no iría en contra del proceso de integración. De hecho, siempre que la UE ha progresado en materias donde se afectaba a la soberanía nacional, como pudieran ser los casos de la moneda única (Euro) o la ratificación del acuerdo Schengen para el tema de las visas, ha sido a través de un grupo pionero, ${ }^{75}$ y sin la participación del Reino Unido. En este sentido tendríamos que recordar que aunque exista el peligro de división en el seno de la UE, las reformas más relevantes casi nunca se han llevado a cabo de manera unánime. Por tanto, consideramos que el peligro estribaría más bien en la posibilidad que se registre un estancamiento que finalmente afecte al espíritu integracionista del proceso de integración europea en el ámbito de la seguridad y defensa.

La CEP podría ofrecer el marco legal necesario para restaurar la relación existente entre la PCSD y el proceso de integración europea, ya que hasta ahora el debate se ha centrado más en el tema de las capacidades militares al servicio de la UE. De hecho, y si nos centramos en el tema del Pooling podemos percatarnos de que el debate se ha vinculado más a la discusión sobre cómo esta modalidad de cooperación podía servir para compartir y ahorrar dinero. En relación a esto último, la CEP podría servir además como plataforma para homologar el nivel de responsabilidad internacional que la UE está dispuesta a asumir con el nivel de capacitación militar que la UE necesitaría para poder desempeñar adecuadamente dicho rol. De hecho, los Poolings presentan el potencial suficiente como para conseguir que la PCSD pueda convertirse en una política realmente integrada que permita a la UE cumplir correctamente con sus obligaciones en la escena internacional de manera que pueda convertirse en un proveedor de seguridad a escala global. Dicha transformación será complicada sin la participación y conjunción de esfuerzos por parte de las grandes potencias europeas como son Alemania, Francia y el Reino Unido.

En este sentido, lo importante es destacar que la UE ha demostrado su voluntad de contar con un marco estratégico común, con una sola voz y con una misma interpretación en cuanto a su política exterior y de seguridad se refiere, con lo cual podemos considerar que estamos en condiciones de poder interpretar y esperar los futuros desarrollos que este marco estratégico registre a medio y largo plazo. Estos futuros desarrollos nos servirán para poder comprobar los cambios en cuanto al papel que vaya asumiendo la UE en el contexto internacional como consecuencia de la mejora de la capacitación y gestión defensiva, que se deriven de la aplicación y funcionamiento del mecanismo de la cooperación estructurada permanente. Al mismo tiempo nos permitirá comprobar si la UE es capaz de superar la

\footnotetext{
${ }^{75}$ Sirva de ejemplo la propuesta del "Euro-grupo de la Defensa" formulada por el Senado francés el pasado 3 de julio de 2013, donde apuesta por la formación de un grupo pionero para poder pasar de la Europa de la Defensa a una Defensa europea. Dicho euro-grupo encajaría perfectamente con la idea de la CEP. A destacar también el hecho de que sugiere la creación de una especie de libro blanco de la defensa que afecte únicamente a este grupo de Estados pioneros, en http://www.senat.fr/rap/r12-713/r12-7131.pdf.
} 
contradicción de querer ser un actor global sin dotarse al mismo tiempo de los medios que le permitan contribuir a la configuración de un sistema internacional en recomposición y asumir las responsabilidades inherentes a un actor global. 